\title{
Narcissism, self-esteem, communication apprehension, and need for affiliation: difference between social networking site users and non-users
}

\begin{abstract}
Nowadays, people are increasingly using social networking sites to initiate and maintain friendships, obtain social support and gather data. Personal traits could potentially drive people to join social networking sites as well as indulge in other related behaviors. This study aims to examine whether people with the need for affiliation, narcissism, self- esteem and communication apprehension are more likely to join social networking sites. Data for the current study were collected using convenience sampling; the sample consisted of undergraduate students studying at three private universities in Tehran, Iran. We used IBM SPSS 20 to run logistic regression statistics to test the research hypotheses developed for this study based on the responses from 284 respondents. The results of this study reveal that selfesteem, communication apprehension and the need for affiliation are significant predictors for social networking site usage while narcissism is not.
\end{abstract}

Keyword: Social networking sites; Narcissism; Self-esteem; Communication apprehension; Need for affiliation 